\title{
Artificial Neural Network Model to Predict Anchored Pile-Wall Displacements on Istanbul Greywackes
}

\author{
Özgür YILDIZ ${ }^{1}$ \\ Mehmet M. BERILGEN²
}

\begin{abstract}
The greywackes are the common soil formation of Istanbul locally known as the Trakya Formation. It is mostly weathered and extensively fractured. The stress relief induced by deep excavations causes excessive displacements in horizontal direction. As a result, predicting excavation-induced wall displacements is critical for avoiding collapse. The aim of this study is to develop an Artificial Neural Network (ANN) model to predict anchored-pile-wall displacements at different stages of excavation performed on Istanbul's greywacke formations. A database was created on excavation and monitoring data from 11 individual projects. Five variables were used as input parameters, namely, excavation depth, maximum ground settlement measured behind the wall, system stiffness, standard penetration test $\mathrm{N}$ value of the soil depth, and index-of-observation. The proposed model was trained, validated, and tested. Finally, two distinct projects were numerically modeled by applying the finite element method (FEM) and then used to test the performance of the ANN model. The displacements predicted by the ANN model were compared with both the computed values obtained from the FEM analysis and in situ measured displacements. The proposed ANN model accurately predicted the displacement of anchored pile walls constructed in greywackes at different stages of excavation.
\end{abstract}

Keywords: Artificial neural network, anchored pile walls, finite element method, wall displacement, Istanbul greywackes.

\section{INTRODUCTION}

Because of the increase in urban populations, deep excavations are often required in metropolitan areas. Such excavation projects rely on rigorous analyses based on geotechnical investigations and laboratory experiments. Changes in excavation-induced stress trigger horizontal and vertical ground movements in and around the excavation area. Therefore,

Note:

- This paper has been received on December 4, 2018 and accepted for publication by the Editorial Board on April 22, 2019.

- Discussions on this paper will be accepted by September 30, 2020.

- https://dx.doi.org/10.18400/tekderg.492280

1 Department of Civil Engineering, Yıldız Technical University, Istanbul, Turkey ozgur.yildiz@std.yildiz.edu.tr- https://orcid.org/0000-0002-3684-3750

2 Department of Civil Engineering, Yıldız Technical University, Istanbul, Turkey berilgen@inm.yildiz.edu.tr- https://orcid.org/0000-0001-6544-011X 
accurate prediction of displacements becomes crucial to ensure the safety and serviceability of surrounding properties.

In some of the earliest works, Peck [1] investigated ground-surface settlements around excavations and subdivided the ground settlements according to the soil type and workmanship. Later, Mana and Clough [2] provided a simplified method to predict movements for braced cuts in clay and provided a relation between wall movements and the safety factor against basal heave. Finno et al. [3] investigated the performance of deep excavations in clay, and Clough and O'Rourke [4] carried out an in situ investigation of wall movements using a database containing information on conventional and new earth-retaining systems. Whittle et al. [5] applied a finite element analysis on braced excavations to predict excavation-induced soil deformations and applied the MIT-E3 effective stress soil model to describe the behavior of clay. They found that post-construction deformations led to differences between predicted and measured wall movements. Hashash and Whittle [6] performed an extensive set of numerical experiments to investigate deformations of a braced diaphragm wall in a deep clay deposit. One result of their study is that the effects of excavation depth and support conditions on ground movements are now given in design charts. Hsieh and $\mathrm{Ou}$ [7] proposed a method that provides good predictions of ground-surface settlements. Long [8] used a database containing several case histories to examine ground movements due to deep excavations and deduced remarkable conclusions for retaining walls in stiff and soft soils with different levels of safety factors against basal heave. Hwang et al. [9] studied the performance of wall systems by focusing on toe movements and reducing wall displacements using buttresses. Wang et al. [10] studied the relationship between ground settlements and wall displacements. Bolton et al. [11] studied ground movements and provided a set of design charts giving soil deformability, wall stiffness, and excavation geometry as a function of the soft soil depth.

The accuracy of current ground movement predictions depends on the accuracy of the soil behavior models and the parameters used [12]. In some cases, soil parameters are poorly defined, the behavior models do not reflect the in situ soil conditions, and/or the problem is too complex to be described in mathematical form. Researchers overcome such problems by using experimental data in computational processing methods. Modern techniques such as fuzzy systems and neural networks have been used to develop data-based models, which are capable of learning and recognizing trends in data patterns [13]. For example, Ghaboussi et al. [14] developed an auto-progressive algorithm to extract material behavior by exploiting force and displacement measurements, and Jan et al. [12] developed a neural network model to predict displacements of diaphragm walls. The model developed by Jan et al. [12] was based on training using wall-displacement data from 18 case histories and considered excavation stages and accurate predictions of wall displacements obtained from simulations at different stages of the excavation. Hashash et al. [15] developed a neural-network-based model to estimate ground deformations in a staged construction of a deep excavation. In another work, Hashash [16] used a self-learning simulation system to extract soil information from lateral wall deformations and surface-settlement measurements of deep excavations. Song et al. [17] used an inverse analysis approach that combined synthetically generated measurements including lateral wall displacements with surface settlement to extract soil behavior. Yildiz et al. [18] developed a neural-network approach to estimate the total lateral thrust on strip-loaded retaining walls. Johari et al. [19] established a genetic-based model to estimate lateral wall displacements of retaining walls using a database including 240 cases. 
In recent years, many high-rise buildings, underground parking lots, and subway stations have been constructed in Istanbul mainly in the local soil formation-known as Istanbul greywackes. Greywackes are characterized by a high degree of weathering, with intercalated sandstone, siltstone, and claystone layers. Excavations in greywackes induce excessive wall movements, causing major problems. Although researchers have already applied artificial neural network (ANN)-based models to predict movements in soft soils, here we present an ANN-based model to predict displacements of anchored pile walls constructed on Istanbul's greywackes. In this study, a database containing information and monitoring data from 11 independent excavation projects in Istanbul was established and an ANN model was developed to predict lateral wall displacements. Four parameters that influence the performance of anchored pile wall as well as the index-of-observation were used as input variables. The created database was then used to train, validate, and test the model. The accuracy of the proposed prediction model was evaluated on the basis of mean square error (MSE) and correlation coefficient (R) values. Finally, two excavation projects not included in the database were used as testing cases. The wall displacements for these testing cases were predicted by applying the developed ANN model, and then, the excavation cases were also numerically modeled by the finite element method (FEM). The lateral displacements predicted by the ANN model were compared with the computed values obtained from the FEM analysis and in situ measurements to examine its performance.

\section{CHARACTERIZATION OF THE GREYWACKES}

A detailed geotechnical survey was carried out by the Istanbul Metropolitan Municipality to identify geological formations in Istanbul [20], in 2007. As a result of this comprehensive work, 24 different local soil and rock formations were identified. The Trakya formation encountered in the study area is known to have been affected by intense tectonic events and has a variety of strike-slip faults, folds, fractures, and joints every few meters. This formation is characterized by a sedimentary greywacke containing intercalated yellowish-brown-todark-gray sandstone, siltstone, and claystone. The Trakya formation can be seen as highly fractured and weathered and exhibits closely to moderately spaced discontinuities. The strength properties of the rock material are in the range of weak to strong. Sandstone is the.

Table 1 - Average characteristic properties of formations.

\begin{tabular}{|c|c|c|c|c|c|c|c|}
\hline $\begin{array}{l}\text { Local } \\
\text { name }\end{array}$ & $\begin{array}{c}\text { Definition of } \\
\text { formation }\end{array}$ & $\begin{array}{c}\mathrm{c}^{\prime} \\
(\mathrm{kPa})\end{array}$ & $\Phi^{\prime}\left({ }^{\circ}\right)$ & $\begin{array}{l}\Psi \\
\left({ }^{\circ}\right)\end{array}$ & $\mathbf{v}$ & $\begin{array}{c}E \\
\left(k N / m^{2}\right)\end{array}$ & $\begin{array}{c}\gamma \\
\left(k N / m^{3}\right)\end{array}$ \\
\hline Fill & New and old, man-made material & 5 & 28 & 0 & 0.2 & 20.000 & 18 \\
\hline Avc1lar & Sand/sand-stone, clay/clay-stone & 0 & 41 & 10 & 0.2 & 65.000 & 22 \\
\hline \multirow{3}{*}{ Trakya } & Fresh/slightly weathered greywacke & 157 & 39 & 0 & 0.2 & 300.000 & 27 \\
\hline & Moderately weathered greywacke & 68 & 32 & 0 & 0.2 & 90.000 & 24 \\
\hline & Completely weathered greywacke & 5 & 28 & 0 & 0.2 & 15.000 & 19 \\
\hline
\end{tabular}

c': effective cohesion, $\Phi^{\prime}$ : effective friction angle, $\Psi$ : dilatancy angle, $v$ : Poisson's ratio, E: deformation modulus, $\gamma$ : unit weight 
most common rock type in this formation, and limestone and conglomerate interbeds or lenses are occasionally found between the layers. The thickness of the formation varies between 600 and $1700 \mathrm{~m}$ [21]. The overlying deposits, which are variously distinguished as the Gurpinar, Cukurcesme, and Gungoren Formations, have collectively been named as a single unit recently, namely the Avcilar Formation [22]. This formation starts with a basal conglomerate layer and continues upwards with intercalated layers of sand/sandstone and clay/claystone. The properties of the soil formations encountered in the selected project sites are given in Table 1

\section{CASE HISTORIES}

In this study, a database was created on the basis of projects supervised by the Istanbul Metropolitan Municipality. In this context, excavation and monitoring data from seven concourse structures of metro stations, three underground parking lots, and a gymnasium building were collected. Anchored pile walls were used as retaining systems in the investigated excavations. The excavation depth of the cases varied between 11.5 to $35 \mathrm{~m}$. The excavations were supported by $65 \mathrm{~cm}$ and $80 \mathrm{~cm}$ diameter pile walls having $13 \mathrm{~m}$ to 36.5 $\mathrm{m}$ length. Ground anchors served as the supporting system. The bond lengths of the anchors varied between 6 to $10 \mathrm{~m}$, and the total lengths were in the range of 10 to $28 \mathrm{~m}$. The vertical and horizontal spacings of the anchors varied between 1 to $2.5 \mathrm{~m}$ and 1.3 to $5 \mathrm{~m}$, respectively. The average inclination of the anchors is $15^{\circ}$. The number of anchor rows used in the projects varied between 2 and 17 . Three to four $0.5^{\prime \prime}$ and $0.6^{\prime \prime}$ diameter tendons were used. Inclinometers were used to measure the lateral displacement through a borehole casing in the walls. The number of inclinometers used in the projects depended on the geometric configuration of the sections. The excavation-induced settlements were measured by settlement markers installed on the ground behind the wall. The local formations encountered at the project sites were artificial fill layers overlying the Avcilar and Trakya formations. Figure 1 shows the typical geometry of an anchored pile wall and the displacement features, along with the notation used.

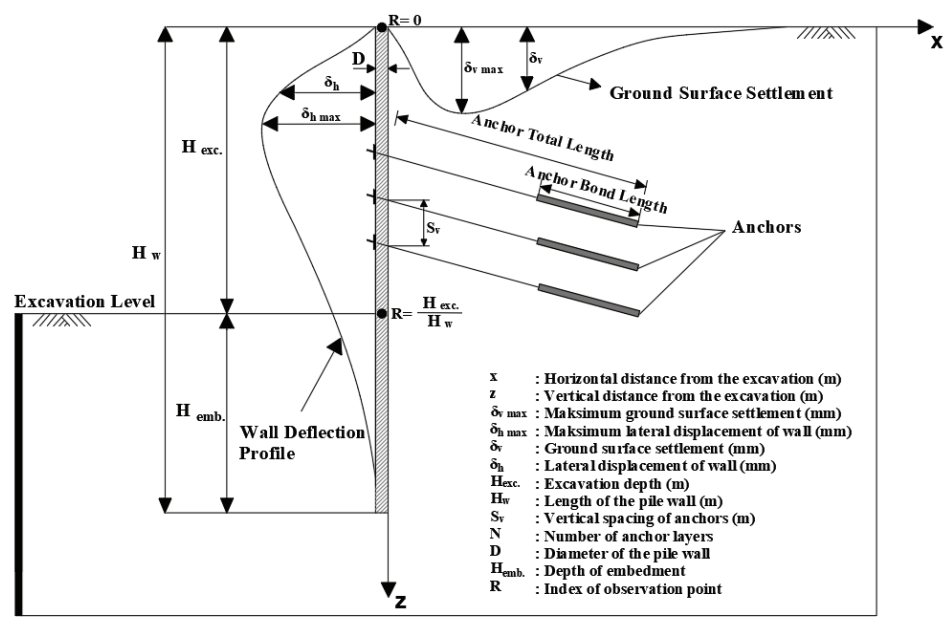

Figure 1 - Definition of variables used to describe the anchored pile walls. 


\section{ARTIFICIAL NEURAL NETWORKS}

ANNs consist of logical software developed to perform basic functions by imitating the working mechanism of the human brain [23]. They can derive new information by learning, remembering, and generalizing. ANNs use their ability to generate new information to produce adaptive solutions to problems that cannot be solved by using a certain algorithm or formulation. The learning ability of ANNs is dependent on different learning algorithms that improve the information at each iteration, thereby achieving more accurate results. [24]

ANNs consist of interconnected process elements called neurons, and each interconnection has a weight. There are different types of ANN architectures. A widely used one is the feedforward network, in which information flows in one direction along the connections, from the input layer via the hidden layer to the output layer. The processing data are fed forward to avoid generating feedback connections [25].

Once a network is structured for an application, it must be trained. In this process, initial weights are chosen at random before the training process begins. Two types of training rules exist, namely, supervised and unsupervised. For supervised training, both inputs and outputs are provided to the network, whereas only inputs are provided for unsupervised training [24]. A feed-forward network is commonly trained using a backpropagation learning algorithm, which is used for applications, and training a neural network with such an algorithm consists of two stages: The first one is the data feed-forward stage in which the output of a neuron is calculated. The output is defined as

$$
\begin{aligned}
& n e t_{j}=\sum_{i=1}^{n} W_{i j} o_{i}+\phi_{i}, \\
& o_{i}=f\left(\text { net }_{i}\right),
\end{aligned}
$$

where $W_{i j}$ is the weight associated with the input element $\mathrm{i}$ in the previous layer to element $\mathrm{j}$ in the current layer, $o_{i}$ is the output of element $i$ in the previous layer, $\phi_{i}$ is the threshold of element $\mathrm{j}$ in the current layer, and $\mathrm{f}$ is the activation function that processes inputs to determine outputs. The activation function $\mathrm{f}$ is usually a nonlinear function. Herein, the sigmoid function is used as activation function because it is continuous and differentiable. Its nonlinearity makes it the most frequently used function in ANN applications. The function $\mathrm{f}$ generates a value between 0 and 1 for each input. It is given by

$$
f(x)=\frac{1}{1+e^{-x}}
$$

In the second stage, after the feed-forward network processes the inputs, the backpropagation algorithm compares the resulting outputs with the desired outputs. The errors are then propagated back through the system, and weights are adjusted. The error function for the system is given by 
$e_{i}=d_{i k}-y_{i k}$

$E=\frac{1}{2} \sum_{i=1} \sum_{k=1} e_{i k}^{2}$,

where $d_{i k}$ is the desired output of node $\mathrm{k}$ for instance $\mathrm{i}$ and $y_{i k}$ is the calculated output of node $\mathrm{k}$ for instance $\mathrm{i}$. The backpropagation algorithm serves to minimize the fitness function, and since this function depends on the network weight, the algorithm consists of processes to optimize the weights. The backpropagation algorithm, which uses the gradient-descent approach to optimize the weights, is defined as

$\Delta w_{i j}=-\gamma \frac{\partial E(w)}{\partial w_{i j}}$

where the learning rate $\gamma$ is a constant between 0 and 1 [26].

\section{ESTABLISHING THE ANN MODEL}

Stress changes induced by a deep excavation inevitably trigger displacements. Herein, an ANN model is developed to predict the displacements in anchored pile walls constructed on Istanbul greywackes by learning from the monitoring data. The displacement data cover 39 sections of 11 anchor-supported pile walls, each section being treated individually. As proposed by Jan et al. [12], each anchored pile wall is discretized into 18 uniform intervals with 19 nodal points. An index-of-observation, $\mathrm{R}$, is defined as the ratio of the depth of the observed segment to the wall length. Altogether, $741(39 \times 19)$ instances were generated to train, validate, and test the network. The primary reason for applying the ANN model was to predict displacements of anchored pile walls constructed on Istanbul greywackes prior to construction as well as during the early and later stages of the activity. A properly established ANN model will accurately predict the wall displacements at each excavation stage. A flowchart of the ANN model is given in Figure 2.

The multilayer perceptron ANN model consists of three layers: an input layer, a hidden layer, and an output layer. The input layer contains five input parameters, namely, the depth of excavation $\left(\mathrm{H}_{\mathrm{exc}}\right)$; measured maximum ground settlement behind the wall $\left(\delta_{\mathrm{v} \max }\right)$; wall stiffness (EI); the SPT-N value of the observed soil depth; and the index of observation (R). The number of hidden layers can be changed according to the network, but the time required for the calculation and the complexity of the network both increase with the number of hidden layers. Accordingly, one hidden layer was used in this model. A series of trial-and-error processes with different numbers of neurons (between 5 and 40) was tested to find the optimum number of neurons in the hidden layer. The best performance was obtained with 15 neurons. The output layer consists of one neuron; $\delta_{\mathrm{h} \text { max }}$, the maximum lateral displacement of the observation point. The available data were divided into three subsets, that is, training, validation, and testing sets. In this study, $80 \%$ of the 741 samples (593 randomly selected 


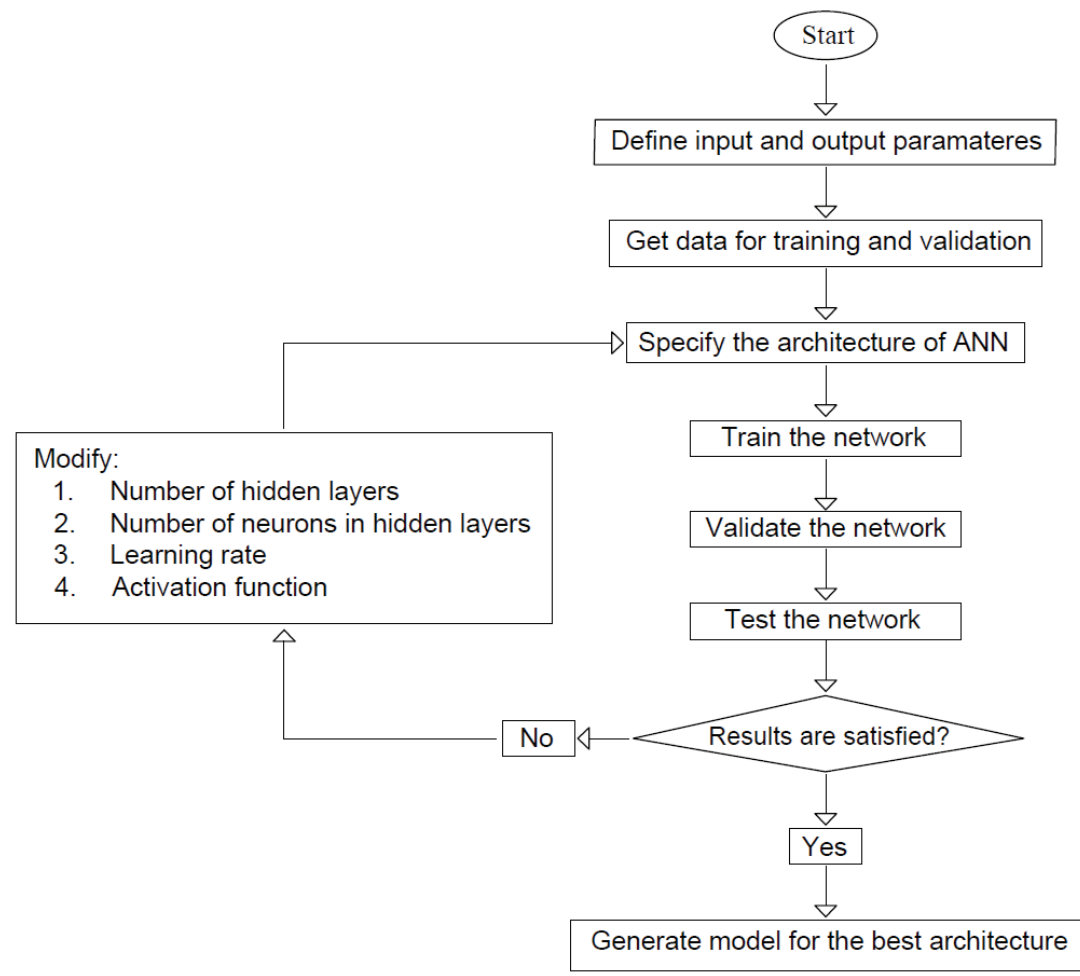

Figure 2 - Flowchart of the ANN model.

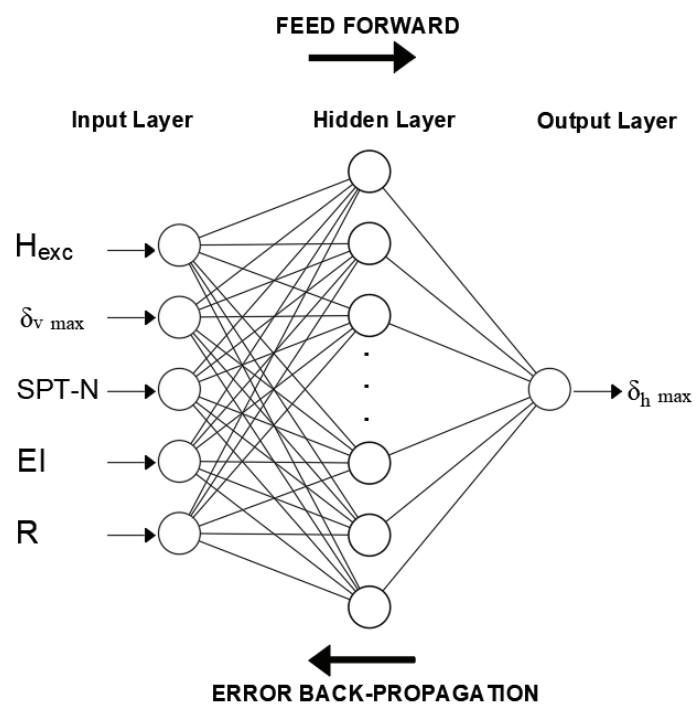

Figure 3 - Typical architecture of a feed-forward network with one hidden layer. 
data) was used for training, 10\% (74 randomly selected data) for validation, and 10\% (74 randomly selected data) for testing of the developed network to predict the lateral displacements. The most commonly preferred algorithm [27], the feed-forward backpropagation algorithm, was used during the training process. The Levenberg-Marquardt algorithm, which is fast and has stable convergence and provides numerical solutions to nonlinear functions, was used in the training stage. In the hidden layer, the best performance of the model was obtained with the sigmoid function, which is a continuous and nonlinear function. The optimal ANN model was determined on the basis of the MSE and R values. Figure 3 shows the architecture of the developed feed-forward network.

\section{COMPUTATIONAL RESULTS FOR THE ANN}

A database containing 11 case histories of deep excavations was used to train, validate, and test the developed ANN model. The accuracy of the predicted wall displacements was determined by comparing them with the results of in situ measurements. Figure 4 shows the regression curves obtained for the network at the training, validation, and testing stages as well as during the entire process. The in situ measurements are shown on the x-axis, labeled as "Target," whereas the predicted displacements are given on the y-axis, labeled as "Output." The linear output demonstrates the success of the prediction model. The correlation coefficients between the maximum measured wall displacements and the predicted wall

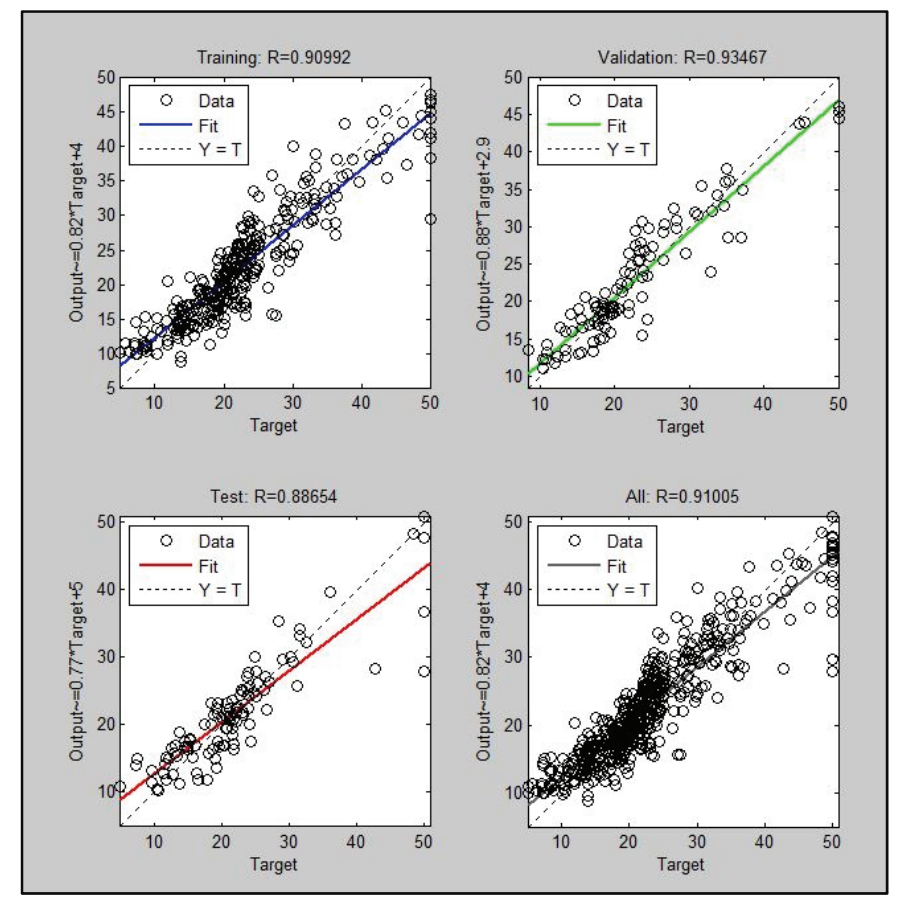

Figure 4 - Regressions curve obtained for the network at the training, validation, and testing stages as well as during the entire process. 
displacements for the training, validation, and testing stages were 0.9099, 0.9347, and 0.8865 , respectively, whereas the cumulative correlation coefficient for all the stages was 0.9101 . The high correlation coefficients between the measured and predicted settlements obtained for all the data sets demonstrate that the adopted model performs well. The MSE values determined for the training, validation, and testing stages were 15.15, 9.65, and 17.44, respectively, showing a close relationship between the measured and ANN-predicted displacement values. The best validation performance obtained at epoch 20 (Figure 5). Ranges of test parameters with basic statistics used for ANN modelling can be seen in Table 2.

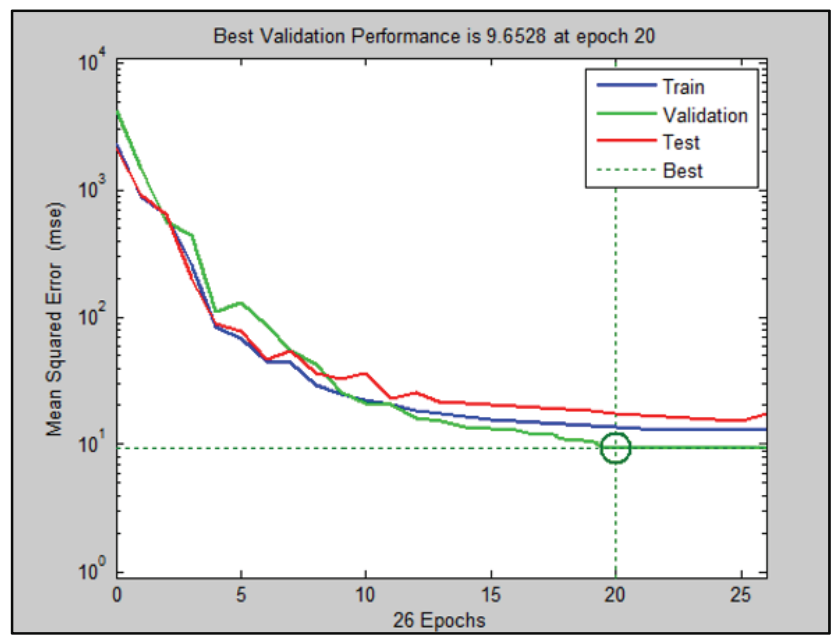

Figure 5 - MSE vs. number of epoch for validation phase

Table 2 - Ranges of test parameters with basic statistics

\begin{tabular}{|c|c|c|c|c|c|}
\hline $\begin{array}{c}\text { Number } \\
\text { of } \\
\text { datasets }\end{array}$ & $\begin{array}{c}\text { Testing } \\
\text { Parameters }\end{array}$ & Maximum & Minimum & Mean & STD \\
\hline \multirow{5}{*}{$\begin{array}{c}741 \\
\text { samples }\end{array}$} & $\mathrm{H}_{\mathrm{exc} .}(\mathrm{m})$ & 35 & 9 & 19.5 & 6.2 \\
\hline & $\delta_{\mathrm{v} \max }(\mathrm{mm})$ & 44 & 2 & 9 & 11 \\
\hline & SPT-N & $>50$ & 5 & 27 & 12 \\
\hline & $\mathrm{EI}\left(\mathrm{kNm}^{2} / \mathrm{m}\right)$ & 3.110 .000 & 115.000 & 2.510 .000 & 534.000 \\
\hline & $\mathrm{R}$ & 32 & 0 & 1.60 & 3.1 \\
\hline
\end{tabular}

\section{TESTING CASES}

Excavation sites not included in the database were used to validate the performance of the developed ANN model. In this context, the excavations of the two metro stations were selected as testing cases. The lateral displacements for these two stations were first predicted by the developed ANN model and then calculated by numerical modeling using the FEM method. 
Table 3 - Testing cases used to evaluate the ANN model.

\begin{tabular}{|c|c|c|c|c|c|c|c|c|c|c|}
\hline $\begin{array}{l}\text { Project } \\
\text { name }\end{array}$ & Section & $\begin{array}{l}\text { Wall } \\
\text { type }\end{array}$ & $\begin{array}{l}\text { Soil } \\
\text { forma- } \\
\text { tion }\end{array}$ & $\begin{array}{c}\text { Soil } \\
\text { profile }\end{array}$ & $\begin{array}{l}\mathrm{H}_{\mathrm{e}} \\
(\mathrm{m})\end{array}$ & $\begin{array}{l}\mathrm{H}_{\mathrm{w}} \\
(\mathrm{m})\end{array}$ & $\begin{array}{c}\mathrm{H}_{\text {emb }} \\
(\mathrm{m})\end{array}$ & $\begin{array}{c}\delta_{\operatorname{vmax}} \\
(\mathrm{mm})\end{array}$ & $\begin{array}{c}\delta_{\text {hmax }}( \\
\mathrm{mm})\end{array}$ & $\begin{array}{c}\mathrm{EI} \\
\left(\mathrm{kNm}^{2 /}\right. \\
\mathrm{m})\end{array}$ \\
\hline \multirow{4}{*}{ Case-I } & $2 \mathrm{~A}$ & \multirow{4}{*}{$\begin{array}{l}\text { Multi } \\
\text { anchor } \\
\text { ed } \\
\text { bored } \\
\text { pile, } 65 \\
\text { cm }\end{array}$} & \multirow{4}{*}{$\begin{array}{l}\text { Avcilar, } \\
\text { Trakya }\end{array}$} & \multirow{4}{*}{$\begin{array}{l}\text { Weathered } \\
\text { claystone, } \\
\text { mudstone }\end{array}$} & 25 & 26 & 1 & 5 & 26 & \multirow{4}{*}{115000} \\
\hline & $4 \mathrm{C}$ & & & & 20 & $\begin{array}{c}22 . \\
5\end{array}$ & 2.5 & 30 & 21 & \\
\hline & $5 \mathrm{E}$ & & & & 19.5 & 20 & 0.5 & 38 & 5 & \\
\hline & 6 & & & & 30.5 & 36 & 5.5 & 9 & 11 & \\
\hline \multirow{3}{*}{ Case-II } & $2 \mathrm{G}$ & $\begin{array}{l}\text { Multi } \\
\text { anchor } \\
\text { ed } \\
\text { bored } \\
\text { pile, } 65 \\
\text { cm }\end{array}$ & \multirow{3}{*}{ Trakya } & \multirow{3}{*}{$\begin{array}{l}\text { Weathered, } \\
\text { fractured } \\
\text { sandstone }\end{array}$} & 16.5 & 19 & 2.5 & 45 & 27 & 115000 \\
\hline & $6 \mathrm{~A}$ & $\begin{array}{l}80 \mathrm{~cm} \\
\text { diameter } \\
\text { bored } \\
\text { pile }\end{array}$ & & & 16.5 & $\begin{array}{c}19 . \\
5\end{array}$ & 3 & 4 & 15 & 312500 \\
\hline & 10 & $\begin{array}{c}\text { Multi } \\
\text { anchored } \\
\text { bored } \\
\text { pile, } 65 \\
\mathrm{~cm}\end{array}$ & & & 21.5 & 25 & 4.5 & 44 & 20 & 115000 \\
\hline
\end{tabular}

In order to observe the ground profile and to determine the excavation support system, at the project sites of case I and case II, 3 boreholes for each with the depth of $35 \mathrm{~m}$ and $30 \mathrm{~m}$ were performed, respectively. A set of laboratory and in situ tests were performed to determine the geotechnical parameters. Both testing cases were constructed on Istanbul greywackes, and anchored pile walls were used as retaining systems in these projects. The plan for case I was rectangular (length: $61.65 \mathrm{~m}$, width: $35.65 \mathrm{~m}$, Figure 6.a). The excavation was completed in eight stages, and the final excavation depth varied between 19.5 and $30.5 \mathrm{~m}$. Cut-and-cover construction method was applied, and according to the geometric configuration of the excavation, four different pile sections with different excavation depths and wall lengths were identified. The diameter of the pile wall was the same for each section, and the installation angle of the anchors ranged from $15^{\circ}$ to $30^{\circ}$. The soil profile at the site consisted of an artificial fill layer between 0 and $1.50 \mathrm{~m}$, a sandy-clay layer between 1.50 to $3.50 \mathrm{~m}$, a clayeysand layer between 3.50 and $6.50 \mathrm{~m}$, a clayey-gravel-and-sand layer between 6.50 to $10.50 \mathrm{~m}$, and an intercalated layer (containing claystone and mudstone) between 10.5 and $32 \mathrm{~m}$. The groundwater table was measured at $8.15 \mathrm{~m}$ (Figure 7.a). Case II excavation was $21.72 \mathrm{~m}$ long and 27.15 to $15.05 \mathrm{~m}$ wide (Figure 6.b), and cut-and-cover construction method was applied here as well. In this case, the excavation was carried out in seven stages, and the final depth of excavation varied between 16.5 and $21.5 \mathrm{~m}$. Three sections with different geometric configurations were modeled. The diameter of the piled wall varied depending on the 
Table 4 - Properties of the anchored pile walls for the excavation of testing cases I and II.

\begin{tabular}{cccccccc}
\hline $\begin{array}{c}\text { Project } \\
\text { name }\end{array}$ & $\begin{array}{c}\mathrm{S}_{\mathrm{v}} \\
(\mathrm{m})\end{array}$ & $\begin{array}{c}\mathrm{S}_{\mathrm{h}} \\
(\mathrm{m})\end{array}$ & $\begin{array}{c}\text { Number } \\
\text { of anchor } \\
\text { rows }\end{array}$ & $\begin{array}{c}\text { Anchor } \\
\text { length } \\
(\mathrm{m})\end{array}$ & Tendon & $\begin{array}{c}\text { EA } \\
(\mathrm{kN} / \mathrm{m})\end{array}$ & $\begin{array}{c}\text { Allowable } \\
\text { tensile } \\
\text { capacity } \\
(\mathrm{kN})\end{array}$ \\
\hline Case-I & $1.5-2.5$ & $1.5-2.0$ & $6-12$ & $13-26$ & $4 \times 0.6^{\prime \prime}$ & 104000 & 804 \\
\hline Case-II & 2 & 1.75 & $3-8$ & $14-28$ & $4 \times 0.6^{\prime \prime}$ & 84000 & 603 \\
\hline
\end{tabular}

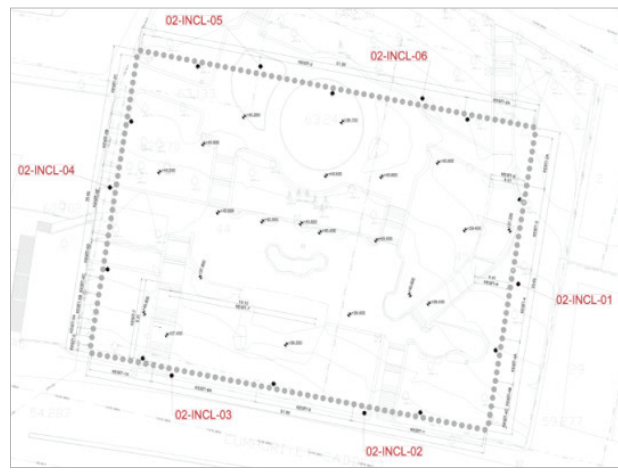

(a)

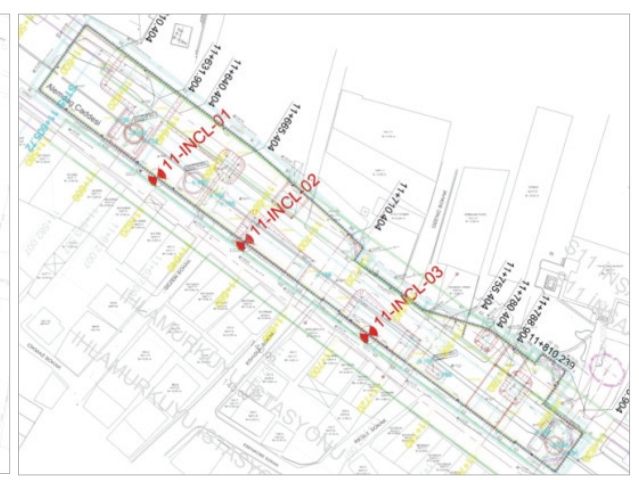

(b)

Figure 6 - Plans of the excavations showing the placements of the inclinometers: (a) case I and (b) case II.

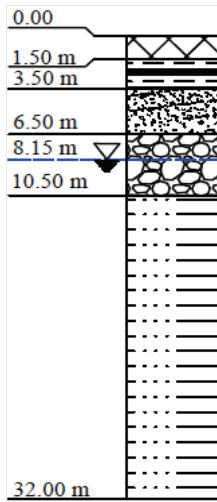

(I) Artificial Fill

(II) Sandy Clay

(III) Clayey Sand

(IV) Clayey Gravel mudstone

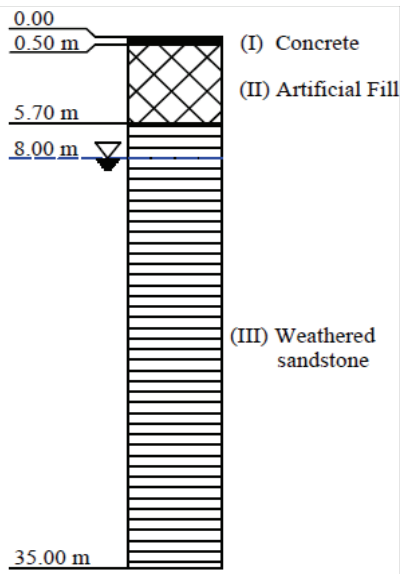

(b)

Figure 7 - Soil profiles for the testing cases: (a) case I and (b) case II. 
geometric configuration of the section. The installation angle of the anchors ranged from $15^{\circ}$ to $25^{\circ}$. The soil profile at the site consisted of a concrete layer between 0 and $0.40 \mathrm{~m}$, a fill layer between 0.40 and $5.70 \mathrm{~m}$, and a weathered and fractured sandstone layer between 5.7 and $35 \mathrm{~m}$. The groundwater table was measured at $8.00 \mathrm{~m}$ (Figure 7.b). Table 3 summarizes the excavation data for cases I and II, and the anchor properties for both cases are given in Table 4. Inclinometers and ground-settlement markers were used to monitor the excavation areas. Six inclinometers were used for case I and three for case II. Typically, the inclinometers were denoted as " $02-I N C L-01$," where " 02 " is the number of the metro station and " 01 " is the number of the inclinometer. Figure 6 shows plans with the placements of the inclinometers marked for each test case.

\section{FINITE ELEMENT MODEL}

The test cases were modeled by applying the 2D plane strain finite element analysis approach employing the PLAXIS 2D v.2018 software package. The boundaries of the finite element models were extended beyond the zone of influence induced by the excavation, in accordance with procedures recommended by $\mathrm{Hsieh}$ and $\mathrm{Ou}$ [7]. 15-node triangular elements were used in the finite element mesh, and to determine the optimum size of the elements and get precise results in a minimized time, different meshing patterns were analyzed. Since the results using fine and very fine meshes were similar, a fine meshing pattern was used. The pile wall was modeled using an elastic plate element, whereas the anchor was modeled as an elastic spring element with the far end having a fixed node. The hardening soil material model, which is an advanced model for simulating the behavior of different types of soil, was utilized. The strength parameters were obtained from laboratory test results, and the engineering parameters used in numerical analysis are given in Table 5. The vertical boundaries of the models were supported by roller fixities to prevent displacements perpendicular to the boundary, whereas the base was supported by hinges. The analyses were performed following the in situ excavation procedures, and the construction was modeled utilizing the staged construction sequence of the software. The soil-pile wall interaction was modeled by the zero-thickness interface element. Along the length of the piled wall, joints were assigned to obtain lateral displacements and displacement profile. Meshed views of the finite element models for both cases are given in Figure 8.

Table 5 - Engineering parameters used in numerical modeling.

\begin{tabular}{c|ccccc|ccc}
\hline \multirow{2}{*}{ Parameter } & \multicolumn{4}{|c|}{ Case-I } & \multicolumn{3}{c}{ Case-II } \\
\cline { 2 - 10 } & \multicolumn{4}{|c|}{ Soil Layer } & \multicolumn{3}{c}{ Soil Layer } \\
\cline { 2 - 10 } & I & II & III & IV & V & II & III \\
\hline $\mathrm{E}_{50}^{\mathrm{ref}}(\mathrm{kPa})$ & 10000 & 15000 & 30000 & 40000 & 75000 & 50000 & 12000 & 90000 \\
\hline $\mathrm{E}_{\text {oed }}^{\mathrm{ref}}(\mathrm{kPa})$ & 10000 & 15000 & 30000 & 40000 & 75000 & 50000 & 12000 & 90000 \\
\hline $\mathrm{E}_{\mathrm{ur}}^{\mathrm{ref}}(\mathrm{kPa})$ & 30000 & 45000 & 90000 & 120000 & 225000 & 150000 & 36000 & 270000 \\
\hline $\mathrm{c}^{\mathrm{ref}}(\mathrm{kPa})$ & 5 & 5 & 25 & 30 & 79 & 200 & 7 & 90 \\
\hline$\phi^{\prime}\left({ }^{\circ}\right)$ & 26 & 21 & 30 & 37 & 39 & 35 & 26 & 40 \\
\hline$\Psi\left(^{\circ}\right)$ & 0 & 0 & 0 & 7 & 9 & 5 & 0 & 10 \\
\hline
\end{tabular}


Table 5 - Engineering parameters used in numerical modeling. (continue)

\begin{tabular}{c|ccccc|ccc}
\hline \multirow{2}{*}{ Parameter } & \multicolumn{4}{|c|}{ Case-I } & \multicolumn{3}{c}{ Case-II } \\
\cline { 2 - 10 } & \multicolumn{4}{|c|}{ Soil Layer } & \multicolumn{3}{c}{ Soil Layer } \\
\cline { 2 - 10 } & I & II & III & IV & V & I & II & III \\
\hline$\gamma_{\text {sat }}\left(\mathrm{kN} / \mathrm{m}^{3}\right)$ & 17,5 & 17 & 19 & 22 & 25 & 24 & 22 & 25 \\
\hline$\gamma_{\text {unsat }}\left(\mathrm{kN} / \mathrm{m}^{3}\right)$ & 17,5 & 17 & 19 & 22 & 25 & 24 & 22 & 25 \\
\hline $\mathrm{K}_{\mathrm{o}}$ & 0,3 & 0,4 & 0,40 & 0,45 & 0,56 & 0,6 & 0,3 & 0,6 \\
\hline$v$ & 0,3 & 0,2 & 0,25 & 0,25 & 0,2 & 0,2 & 0,3 & 0,2 \\
\hline $\mathrm{e}_{\text {init }}$ & 0,5 & 0,5 & 0,5 & 0,5 & 0,5 & 0,5 & 0,5 & 0,5 \\
\hline $\mathrm{R}_{\mathrm{i}}$ & 0,50 & 0,50 & 0,65 & 0,70 & 0,70 & 0,67 & 0,50 & 0,70 \\
\hline
\end{tabular}

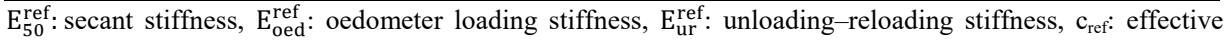
shear strength, $\phi^{\prime}$ : effective friction angle, $\Psi$ : dilatancy angle, $\gamma_{\text {sat }}$ : saturated unit weight, $\gamma_{\text {unsat }}$ : unsaturated unit weight, $\mathrm{K}_{\mathrm{o}}$ : pressure coefficients, $v$ : Poisson's ratio, $\mathrm{e}_{\mathrm{init}}$ : initial void ratio, $\mathrm{R}_{\mathrm{i}}$ : stiffness reduction factor

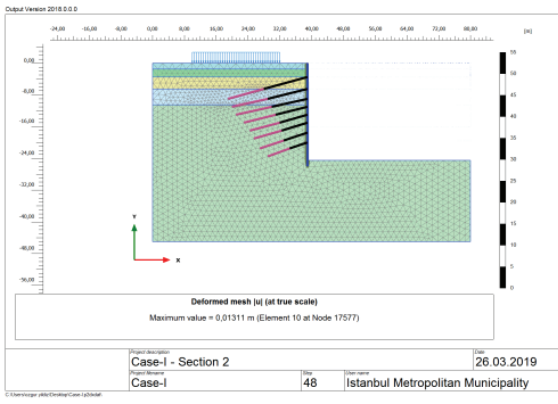

(a)

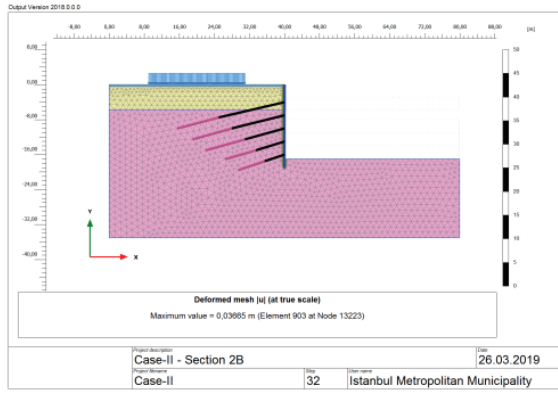

(b)

Figure 8 - Meshed views of the finite element models: (a) case I and (b) case II.

\section{RESULTS}

The lateral displacements predicted by the ANN model for the two testing cases were validated by comparison with calculated values from the FEM analysis and field measurements.

\subsection{Case I}

Figure 9 shows the wall displacements predicted by the ANN model, together with those computed by FEM analysis and measured by the inclinometers as a function of the excavation depth during the initial, middle, and final stages of the excavation. Five inclinometers measured lateral displacements at different sections of the excavation, and for each case, it was seen that as the excavation proceeded, the measured displacements increased and the wall gradually developed a bulging profile. The depths at which the maximum measured 


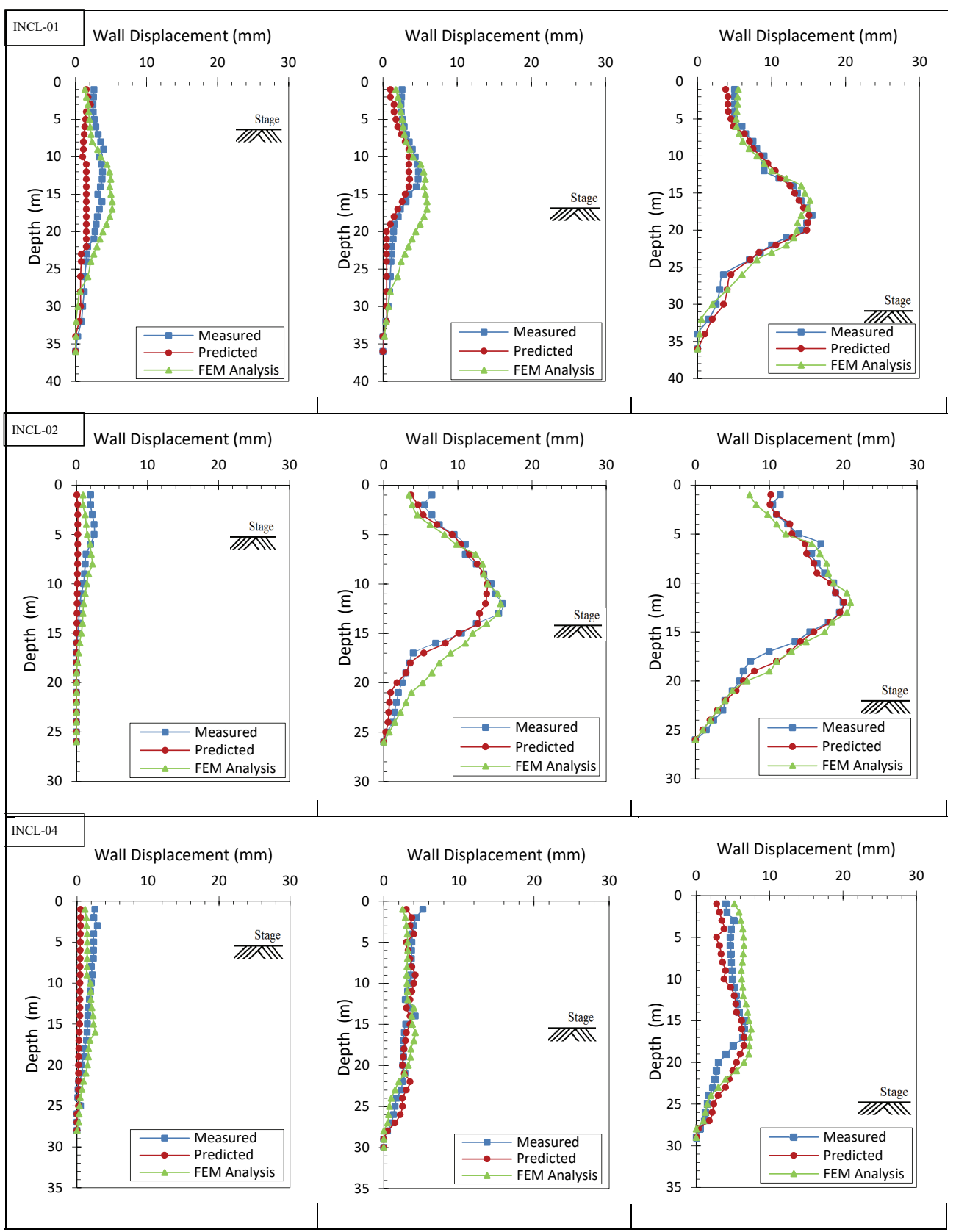




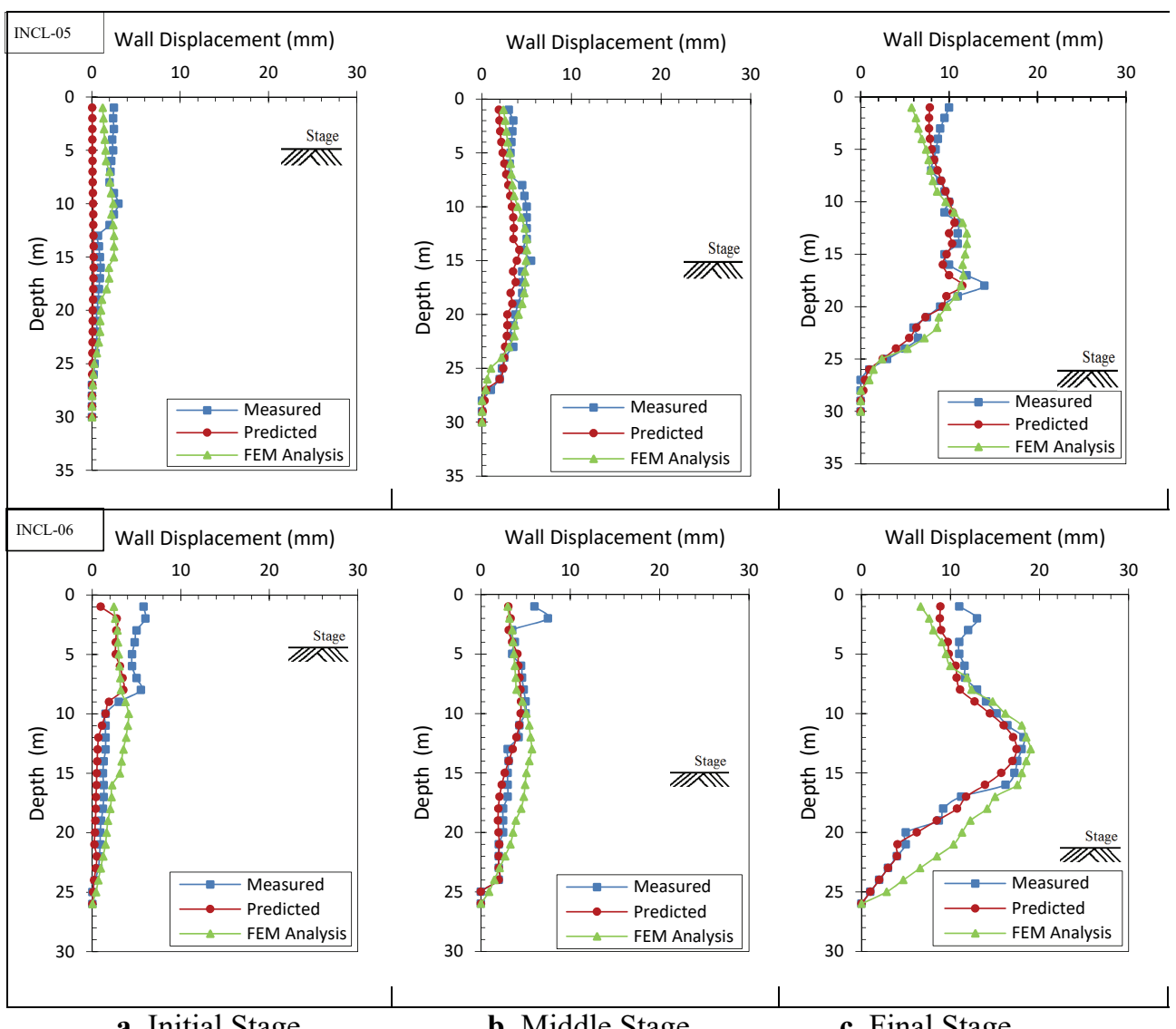

a. Initial Stage

b. Middle Stage

c. Final Stage

Figure 9 - Measured, ANN-predicted, and FEM-computed wall displacements for case I.

displacements occurred were not consistent, and the maximum lateral displacements were measured at different locations along the longitudinal axis. Some of the maximum displacements appeared above the excavation stage, whereas others occurred below it. At the initial excavation stage, in the upper parts of the wall, the displacements measured by the inclinometers were higher than those predicted by the ANN model and obtained from the FEM analysis. The FEM analysis gives the highest displacement values in the middle and lower parts of the wall, whereas the ANN predictions are the lowest ones in this area. The ANN model underestimates the wall displacements in the upper parts of the wall but shows a better performance in the lower parts. The differences between the measured and ANNpredicted displacements at the upper part of the wall can be attributed to the cantilevering excavation stage effect. At the middle excavation stage, the ANN-predicted displacements were very close to those measured by the inclinometers. Also, the displacement profiles matched well for all the inclinometers. In the lower parts of the wall, the displacements calculated by FEM analysis were higher than those measured by the inclinometers, which may be due to poorly defined soil parameters that do not completely reflect in situ conditions. 
At the final excavation stage, the magnitudes of the displacements reached the highest values among all the inclinometers. The ANN-predicted displacements were very close to those measured by INCL-01, INCL-02, and INCL-06, whereas slight differences were observed between the predicted values and the displacements measured using the INCL-04 and INCL05 instruments. However, a sudden increase in the displacement at $18 \mathrm{~m}$ wall depth (measured using INCL-05 and caused by a discontinuity in the extensively fractured greywackes) was successfully predicted by the ANN model. In general, the displacements calculated by FEM analysis were slightly higher than the ANN-predicted and measured values, which may be the result of a lack of reliance of the parameters used in numerical analysis. Overall, the ANN model provides acceptable predictions of the wall displacements. The maximum measured and predicted wall displacements and the shape of the displacement curve match well with the results obtained using all the inclinometers.

Table 6 summarizes the maximum displacements predicted by the ANN model, computed by FEM analysis and measured by the inclinometers. The ANN predicted displacements are very close to those measured by INCL-02 and INCL-04, whereas minor discrepancies were observed between the predicted values and the displacements measured using the INCL-1, INCL-05 and INCL-06. The depths at which the maximum displacements occurred were predicted with high accuracy. The maximum displacements calculated by FEM analysis provide satisfactory agreement with the field measurements.

Table 6 - Summary of the displacement data for Case-I

\begin{tabular}{|c|c|c|c|c|c|c|c|c|c|c|}
\hline \multirow{3}{*}{ Method } & \multicolumn{10}{|c|}{ Case-I } \\
\cline { 2 - 12 } & \multicolumn{2}{|c|}{ INCL-01 } & \multicolumn{2}{|c|}{ INCL-02 } & \multicolumn{2}{c|}{ INCL-04 } & \multicolumn{2}{|c|}{ INCL-05 } & \multicolumn{2}{c|}{ INC-06 } \\
\cline { 2 - 11 } & $\begin{array}{c}\text { Depth } \\
(\mathrm{m})\end{array}$ & $\begin{array}{c}\delta_{\mathrm{h} \max } \\
(\mathrm{mm})\end{array}$ & $\begin{array}{c}\text { Depth } \\
(\mathrm{m})\end{array}$ & $\begin{array}{c}\delta_{\mathrm{h} \max } \\
(\mathrm{mm})\end{array}$ & $\begin{array}{c}\text { Depth } \\
(\mathrm{m})\end{array}$ & $\begin{array}{c}\delta_{\mathrm{h} \max } \\
(\mathrm{mm})\end{array}$ & $\begin{array}{c}\text { Depth } \\
(\mathrm{m})\end{array}$ & $\begin{array}{c}\delta_{\mathrm{h} \max } \\
(\mathrm{mm})\end{array}$ & $\begin{array}{c}\text { Depth } \\
(\mathrm{m})\end{array}$ & $\begin{array}{c}\delta_{\mathrm{h} \max } \\
(\mathrm{mm})\end{array}$ \\
\hline Measured & 1 & 15.5 & 12 & 20 & 15 & 6.5 & 18 & 14 & 12 & 18.5 \\
\hline ANN & 17 & 14.5 & 12 & 20,1 & 18 & 6.6 & 17 & 11,5 & 13 & 16 \\
\hline FEM & 16 & 15.2 & 11 & 20,5 & 16 & 7.5 & 14 & 13 & 13 & 19 \\
\hline
\end{tabular}

\subsection{Case II}

Figure 10 shows the wall displacements predicted by the ANN model, together with those computed by FEM analysis and measured by the inclinometers as a function of the excavation depth during the initial, middle, and final stages of the excavation. Three inclinometers were used to measure the lateral displacements at three distinct sections of the excavation. At the initial excavation stage, the measured wall deflections were slightly larger than the predicted ones for all the inclinometers, regardless of the depth of excavation. The maximum difference between predicted and measured displacements of about $5.5 \mathrm{~mm}$ was observed for INCL-01. Except for the top parts of the wall, the displacements calculated by FEM analysis were usually higher than both the ANN-predicted and measured ones. The differences between FEM results and measured displacements may have been caused by the selected geotechnical parameters that do not fully reflect the field conditions. At the middle excavation stage, the 


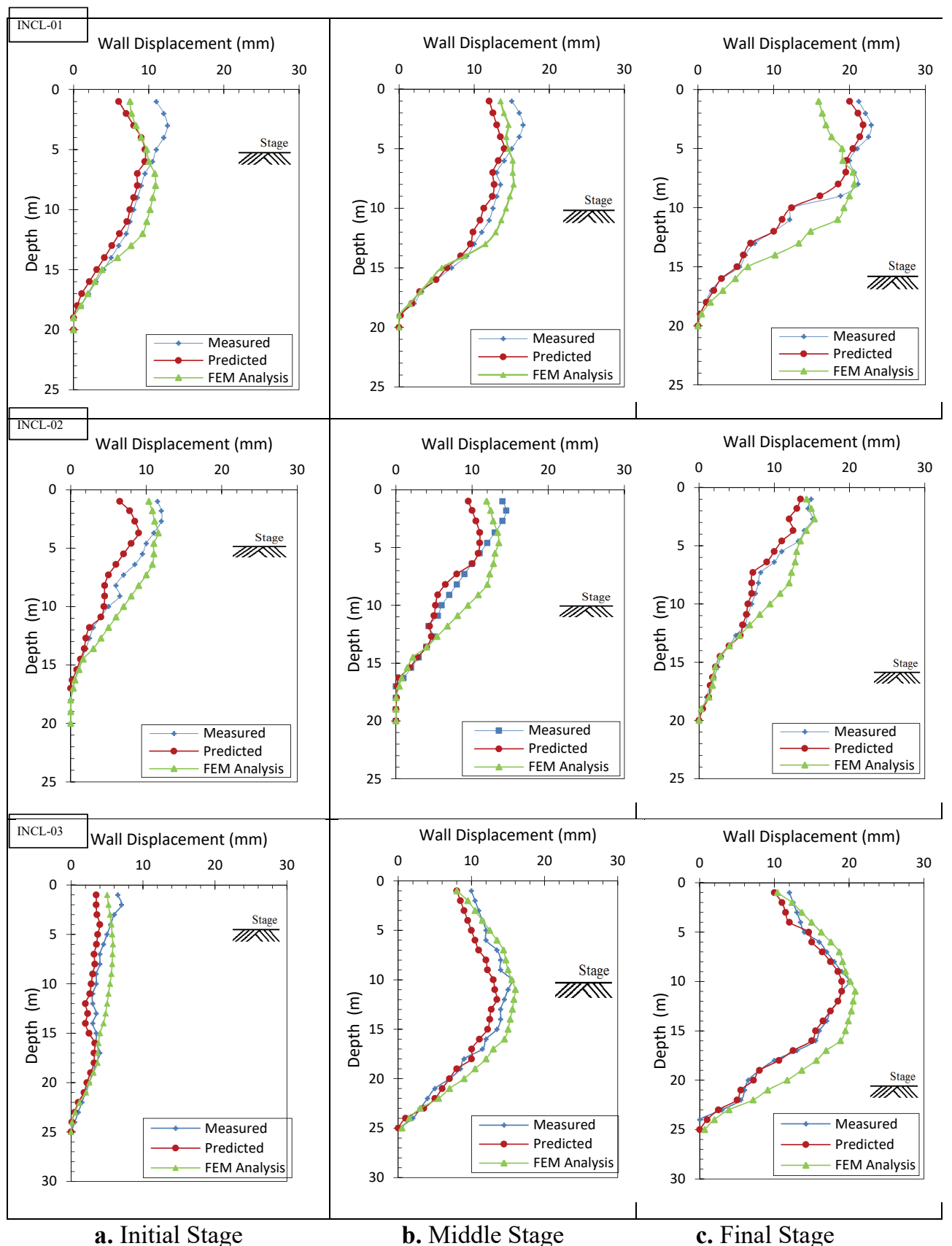

Figure 10 - Measured, ANN-predicted, and FEM-computed wall displacements for case II. 
ANN-predicted wall deflections were lower than the values obtained from the field measurements for the upper parts of the wall, but very close to them for the lower parts. The relatively low predicted displacements could be due to the cantilever excavation stage, which sometimes causes excessive deformations. In the middle and lower parts of the wall, the displacements calculated by FEM analysis were slightly higher than the measured and predicted ones. At the final excavation stage, the differences between the predicted and measured deflections were markedly lower than those observed at the initial and middle stages. Despite the slight differences at the upper parts of the wall, the ANN-predicted displacement profile demonstrates a striking resemblance to the measured displacement profile at the lower parts of the wall. As in the previous excavation stages, the FEM analysis gives higher displacements at the lower parts of the wall compared with the field measurements and the ANN predictions. This is not the case for the upper wall parts. Overall, the wall displacements predicted by the ANN model match well with the maximum measured wall displacements over the entire range of excavation depths.

Table 7 summarizes the maximum displacements predicted by the ANN model, computed by FEM analysis and measured by the inclinometers. The maximum displacements predicted by ANN model agree well with those measured by inclinometers. The depths at which the maximum displacement occurred were successfully predicted. Also, the maximum displacements calculated by FEM analysis are very close to the field measurements.

Table 7 - Summary of the displacement data for Case-II

\begin{tabular}{|c|c|c|c|c|c|c|}
\hline \multirow{3}{*}{ Method } & \multicolumn{6}{|c|}{ Case-II } \\
\cline { 2 - 7 } & \multicolumn{2}{|c|}{ INCL-01 } & \multicolumn{2}{|c|}{ INCL-02 } & \multicolumn{2}{c|}{ INCL-03 } \\
\cline { 2 - 7 } & $\begin{array}{c}\text { Depth } \\
(\mathrm{m})\end{array}$ & $\begin{array}{c}\delta_{\mathrm{h} \max } \\
(\mathrm{mm})\end{array}$ & $\begin{array}{c}\text { Depth } \\
(\mathrm{m})\end{array}$ & $\begin{array}{c}\delta_{\mathrm{h} \max } \\
(\mathrm{mm})\end{array}$ & $\begin{array}{c}\text { Depth } \\
(\mathrm{m})\end{array}$ & $\begin{array}{c}\delta_{\mathrm{h} \max } \\
(\mathrm{mm})\end{array}$ \\
\hline Measured & 3 & 22.9 & 3 & 15.1 & 10 & 15.5 \\
\hline ANN & 3 & 21.8 & 1 & 13.5 & 12 & 13.6 \\
\hline FEM & 8 & 21.4 & 3 & 15.3 & 11 & 16 \\
\hline
\end{tabular}

\section{CONCLUSIONS}

We have developed an ANN model for predicting the displacements of anchored pile walls constructed in Istanbul's greywackes. The new system was trained, validated, and tested using the data collected from excavation projects in Istanbul, conducted by the Istanbul Metropolitan Municipality. The excavations of two distinct metro stations were numerically modeled by FEM, and the computed lateral displacements obtained from this analysis as well as the results of field measurements were used to validate the performance of the ANN prediction model.

The conclusions of our work can be summarized as follows:

1. The developed ANN model can accurately predict the magnitude as well as the location of the maximum wall displacement of anchored pile walls at different stages of excavation. 
2. Some discrepancies observed between the measured and ANN-predicted displacements at the initial stages can be explained by cantilever stage effects.

3. Despite the slight differences between the ANN predictions and the results of the FEM analysis, the performance of the ANN-based model for predicting lateral displacements in Istanbul's greywackes was satisfactory, showing that this procedure can serve as a complementary method to FEM analysis.

4. With the ANN model being trained, tested, and validated using data from previous excavations, this method can be applied to predict anchored pile wall displacements for future projects. Predictions based on initial stage can thus be applied to excavations at subsequent stages.

5. The satisfactory performance of the developed model on Istanbul greywackes confirms the potential of ANN in the field of geotechnical engineering. The proposed model enables learning from previous regional excavations and can be applied to new projects in these areas.

\section{References}

[1] Peck, R.B., Deep excavations and tunneling in soft ground. Proceedings 7th I.C.S.M.F.E. State of Art Sayı., Mexico: 225-290, 1969

[2] Mana, A.I., Clough, G.W., Prediction of movements for braced cuts in clay. J. Geotech. Eng. Div., 107, 759-777, 1981

[3] Finno, R.J., Atmatzidis, D.K., Perkins, S.B., Observed performance of a deep excavation in clay. J. Geotech. Eng., 115(8), 1045-1064, 1989

[4] Clough, G.W., O'Rourke, T.D., Construction induced movements of in-situ walls. Geotechnical special publication: Design and performance of earth retaining structures (GSP 25)., ASCE, Reston, VA, 439-470, 1990

[5] Whittle, A.J., Hashash, Y.M.A., Whitman, R.V., Analysis of deep excavation in Boston., J. Geotech. Eng., 119(1), 69-90, 1993

[6] Hashash, Y.M.A., Whittle, A.J.,Ground movement prediction for deep excavations in soft clay., J. Geotech. Eng., 122(6), 474-486, 1996

[7] Hsieh, P.G., Ou, C.Y., Shape of ground surface settlement profiles caused by excavation., Can. Geotech. J., 35(6), 1004-1017, 1998

[8] Long, M., Database for retaining wall and ground movements due to deep excavations., J. Geotech. Geoenviron. Eng., 127(3), 203-224, 2001

[9] Hwang, R.N., Moh, Z.C., Evaluating effectiveness of buttresses and cross walls by reference envelopes., J. Geoeng. 3(1), 1-12, 2008

[10] Wang, J.H., Xu, Z.H., Wang, W.D., Wall and ground movements due to deep excavations in Shanghai soft soils., J. Geotech. Geoenviron. Eng., 136 (7), 985-994, 2010 
[11] Bolton, M.D., Lam, S.Y., Vardanega, P.J., Ng, C.W., Ma, X., Ground movements due to deep excavations in Shanghai: Design charts., Front. Struct. Civ. Eng., 8(3), 201236,2014

[12] Jan., J.C., Hung, S.L., Chi, S.Y., Chern, J.C., Neural network forecast model in deep excavation., J. Comput. Civil Eng., 16(1), 59-65, 2002

[13] Goh, A.T.C., Goh, S.H., Support vector machines: their use in geotechnical engineering as illustrated using seismic liquefaction data.,Comput. Geotech. 34(5), 410-421, 2007

[14] Ghaboussi, J., Pecknold, D.A., Zhang, M., Haj-Ali, R., Autoprogressive training of neural network constitutive models., Int. J. Numer. Methods Fluids, 42(1), 105-126, 1998

[15] Hashash, Y.M.A., Marulanda, C., Ghaboussi, J., Jung, S., Systematic update of a deep excavation model using field performance data.,Comput. Geotech., 30(6), 477-488, 2003

[16] Hashash, Y.M.A., Marulanda, C., Ghaboussi, J., Jung, S., Novel approach to integration of numerical modeling and field observations for deep excavation., J. Geotech. Geoenviron. Eng., 132(8), 1019-1031, 2006

[17] Song, H., Osouli, A., Hashash, Y., Soil behavior and excavation instrumentation layout, 7th International symposium on field measurements in geomechanics FMGM., Boston, MA., 2007

[18] Yıldız, E., Ozyazıcıoglu, M.H, Ozkan, M.Y., Lateral Pressures on Rigid Retaining Walls: A Neural Network Approach., Gazi Univ. J. Science, 23(2), 201-210, 2010

[19] Johari, A., Javadi, A.A., Najafi, H., A genetic-based model to predict maximum lateral displacement of retaining wall in granular soil., ScienticaIranica, 23(1), 54-65, 2016

[20] Istanbul Metropolitan Municipality Department of Earthquake Risk Management and Urban Development Directorate of Earthquake and Ground Analysis, Microzonation work for the southern European side of Istanbul, Final Report, 1-88, 2007

[21] Eroskay, S.O., Graywackes of Istanbul Region, Proceedings of International Symposium on Design of Supports to Deep Excavations., Turkish Group of Soil Mechanics, Bosphorus University, 41-44, 1985

[22] Yıldırım, M., Tonaroğlu, M., Selçuk, M.E., Akgüner, C., Revised stratigraphy of the tertiary deposits of Istanbul and their engineering properties., B. Eng. Geol. Environ., 72(3-4), 413-420, 2013

[23] Shahin, M., Intelligent computing for modeling axial capacity of pile foundations., Can. Geotech. J, 47(2):230-243, 2010

[24] Öztemel,E., YapaySinirAğları, PapatyaYayıncılık, 29-162, 2012

[25] Haykin, S., Neural Networks: A Comprehensive Foundation, 1,23-71, 2001.

[26] Rojas, R., Neural Networks A systematic Introduction, Berlin, 151-184, 1996

[27] Rummelhart, D.E., Hinton, G.E., Williams, R.J., Learning Internal representation by error propagation., J. Parallel Distrib. Comput., 1(8): 318-362, 1986 